\title{
Research of Visual Communication Design Education Study on the Basis of Field Innovation Strategy
}

\author{
Xuan Wan \\ Shanghai Sanda University, Art and Design School, Shanghai 201209, China \\ wanxuan6669@163.com
}

Keywords: Educational field; field innovation strategy; visual communication design; design education.

\begin{abstract}
One of challenges encountered by visual communication design education transformation from educational technology innovation to teaching field innovation strategy currently. In the paper, the author tries to apply five key points of educational field into visual communication design education. Five teaching field innovation strategies are proposed aiming at the core product of students and relationship network between surrounding dynamic development, namely teaching system environment strategy, teacher-student interactive network strategy, ecological teaching network strategy, boundary resource network strategy and public relations network strategy. The paper aims at exploring and establishing a visual communication design education ecological system 'based on students'.
\end{abstract}

\section{Introduction}

Field theory is one of main theories of sociology, which was proposed by Pierre Bourdieu, a French sociologist. Bourdieu studied many fields, such as aesthetic field, culture field and educational field. A market is regarded as a link in each field. Producers and consumers of symbolic commodity in the field are combined. For example, the field of art includes painters, art work purchasers, critics, museum management personnel, etc.

'Field' and 'education' are combined to generate 'educational field' category, which is an attempt of field explanation on education. It is also a positive exploration of education study in education category construction and methodology development.

Educational field refers to an objective relationship network which is formed among educators, educatees and other education participants as an objective social existence, wherein it is supported by knowledge production, transmission, dissemination and consumption, which aims at people development, formation and improvement fundamentally.

Five key points of educational field can be extracted according to the definition of the above educational field:

1. Three parties in the field: teachers, students and other participants;

2. Students are core products;

3. Market is an important factor;

4. Sustainable development;

5. Relation network

Five key points of educational field are applied in visual communication design education. The author proposes five teaching field innovation strategies aiming at 'student'- a core product that should be tested by the market and the relation network of dynamic development among three parties, respectively including teaching system environment strategy, teacher-student interactive network strategy, ecological teaching network strategy, boundary resource network strategy and public relations network strategy. 


\section{Teaching system environment strategy}

Visual communication design education has the most prominent feature of strong applicability. Therefore, it is necessary to create a teaching system environment stimulating students' 'mind and hand'. The environmental system includes hard environment and soft environment aiming at 'student'-the core product. Hard environment refers to three-in-one 'classroom - studio - laboratory'. Soft environment refers to utilization rate of 'three rooms', configuration of laboratory technicians, management regulation of laboratory, updating and maintenance fund of hardware equipment, etc.

The teaching technology and technology innovation are main directions currently. Hard environment is improved greatly. Equipment is new, and machines are high-end. However, the average utilization rate of new equipment in China is always low. Crucial reasons are summarized. Firstly, laboratory technicians are configured insufficiently, students are not guided during machine operation, and security problems are not guaranteed. The second reason is updating and maintenance expense of hardware equipment. If the equipment utilization rate is high, the updating and maintenance cost is also higher. The third reason is operation management of lab. These are soft environmental problems.

'Good tools are essential things'. Teaching system environment strategy refers that hard and soft environments are grasped together, weak parts are mainly overcome, and 'mind and hand' environment strategy can be created for students.

\section{Teacher-student interactive network strategy}

'Teacher-student interactive network' is one of important relation networks in the educational field theory. Interaction between teachers and students cannot rely on classroom teaching interaction simply, the contact between teachers and students in classroom is limited after all, and classroom teaching interaction is a shallow interaction between teachers and students.

Firstly, a familiar and trusted teacher-student relationship should be established in order to establish a deep teacher-student interactive network. High-quality teacher-student interaction can be naturally produced if high-quality teacher-student emotion is available. Therefore, teachers should spend a lot of energy to observe, understand and adjust each student's learning and living conditions. The teacher should integrate the roles of professional teacher and counselor together. Two points are most important here: firstly, a new teacher-student organization mode should be available. Secondly, teacher quantity should be guaranteed.

A rule strategy is established, which is more persuasive than pure reliance on the teachers' education enthusiasm. The rule guarantees that each teacher can establish a deep relationship between teachers and students continuously. The interactive network can be implemented through the following two modes:

\section{1 'Tutorial system' studio}

Tutorial system studio refers to establishment of a design studio led by a tutor. Each studio should have clear research directions and projects. Tutors can recruit certain amount of students into the studio from three grades, namely sophomore, junior and senior. One set is prepared for each student, and the student should select sub-project consistent with the director of the tutor for project design.

Students and teachers study the project together in the environment, including interaction among students at different grades and interaction between teachers and students. They can be familiar mutually. Deep teacher-student interactive network is naturally formed.

Tutorial system studio is a teacher-student organization mode under a more ideal state. Higher requirements are proposed for teaching sites and teacher quantity. Student layered training plan mode can be considered if ideal conditions are not available.

\subsection{Student layered training plan}

Layered training is implemented on students according to student sources on the basis of factors in the aspects of major attention, learning ability, etc. A part of excellent talents are selected firstly. The professional ability is mainly cultivated. They form a design team with backbone teachers for 
designing projects, participating in design competitions and other specialized activities. Students in the middle class participate in teaching interaction in the classroom mainly, thereby comprehending their employment direction, and fostering their ability of general knowledge. Some students are more blind and sluggish, and they are mainly supervised to complete study and explore their diverse potential.

The teacher-student interactive network strategy has higher feasibility, which is recognized and promoted widely.

\section{Ecological teaching network strategy}

Establishment of ecological teaching network is the most important part of teaching field innovation. The ecological structure of the teaching network includes course system, teaching method, project selection, teacher function positioning, quality evaluation standard, establishment of communication platform, etc.

\subsection{Course system}

Course system of the visual communication design major is divided into 3 major parts- professional basic course, professional core course and comprehensive practice course.

Professional basic course is integrated into four parts, namely humanistic thought, design thought, form rule and professional expression.

Primary application training is implemented through five course modules of professional core courses (namely packaging design module, advertising design module, book design module, brand design module and website APP design module). Figure 1-visual communication design course system diagram:

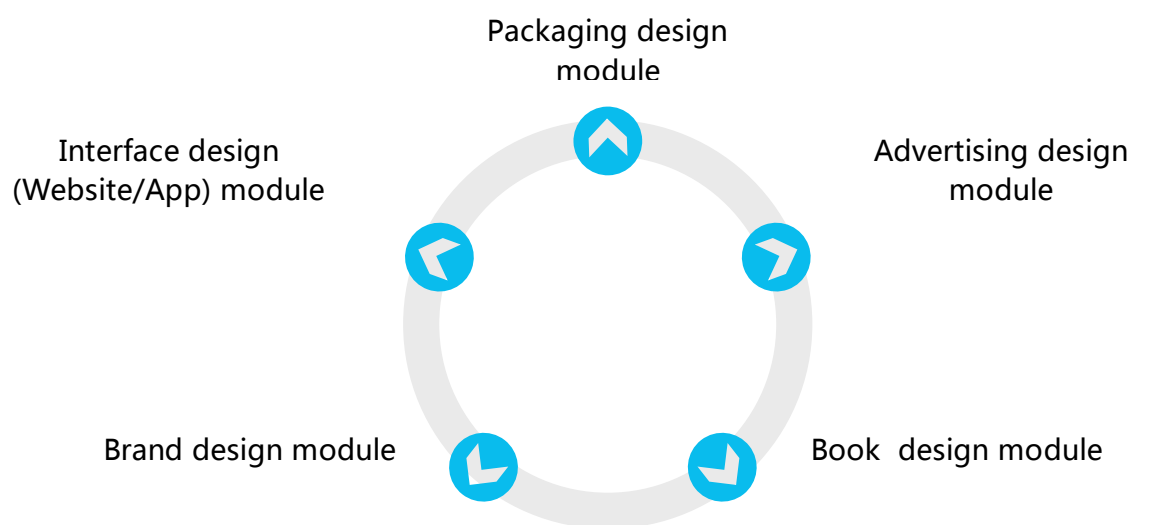

Fig.1-Visual communication design course system diagram

Finally, students can select one main direction from five core modules; they are integrated into the comprehensive practice course and added into the project design of the tutor studio.

\subsection{Teaching methods}

The teaching method can be selected according to teaching effect as reference. The teaching mode with excellent teaching effect and high student work quality is the best teaching mode. The teaching mode under school supervision is standard but inflexible.

The teaching method can be flexible and varied as long as the syllabus of the course is drawn up and reviewed, and the teaching goal is achieved at the end of the course, including brainstorm random teaching method, teacher-student creative experiment, one-to-one chat, free discussion among students, scene infiltration, etc.

\subsection{Project selection}

Tutor professional thought and level can be best embodied in selection of project. Tutors should select own project direction carefully, and lead own student team to study continuously for many years. Students' design vision, understanding on design, and pattern are reflected in the design of own project. 
Topics of visual communication design major are complex and extensive. They are comprehensively designed basically aiming at five carriers, namely packaging, poster, book, brand and website APP, etc. The graduation design projects each year seem to be endless, but they are similar mainly and lack of internal deliberative logic. In conclusion, project positioning, logic, value and sustainability are critical.

Actual situation in different areas and different colleges are combined. Regional economy, community culture, diversified culture, ecological environment, intelligent science and technology, cultural heritage protection and other social topics also can be focused during project selection.

\subsection{Teacher function positioning}

The function of a professional teacher is positioned as a guider, a facilitator and an administrator rather than an indoctrinator. The most important ability of a professional teacher is to know how to motivate students to learn, know how to build a student's self-confidence in study, know how to provide solutions at the student's bottleneck period, allow students to try rather than directly demonstrating results, and know how to guide students grow comprehensively in practice.

Knowledge is updated fast, and the Internet search ability is incredibly powerful in the Internet age. It is difficult for professional teachers to keep pace with the technology of enterprises in their teaching positions. Therefore, professional teachers not only should participate in new technical training, and make efforts to keep pace with times, but also should make clear the function positioning of 'education workers'. Education workers cannot be replaced by knowledge updating. 'Elaborate education' is the core value of the teacher. Professional teachers can cultivate high quality with dedication and enthusiasm. Students are always cores of field innovation strategy.

\subsection{Quality evaluation standard}

The 'student-centered' quality evaluation standard is formed, including teacher title promotion evaluation criteria (not according to paper number, but teaching quality and the participation of public affairs), student scholarship evaluation standard (not according to English scores but moral character and professional course scores), secondary college teaching quality evaluation criterion, student teaching evaluation standards, etc. Open, fair and equal teaching quality evaluation cultures are formed, thereby ensuring sound and sustainable development of education.

\subsection{Establishment of communication platform}

Activities are regularly organized, such as 'design week'. Each tutor's student project achievement exhibition, course work exhibition and graduation design exhibition can be exchanged communicated in the design week. Meanwhile, voting for the most popular teacher, design salon, studio exchange experience, cross-border cooperation design and similar activities are held, thereby cultivating benign competition atmosphere of professional education.

\section{Boundary resource network strategy}

Boundary resources of visual communication design major refer to crossing, infiltration and fusion with other disciplines. A resource network of cross-boundary cooperation is established, such as cross-boundary cooperation of visual communication design with industrial design, product design, environmental design, clothing and costume design and other related majors, interdisciplinary cooperation with communication, network new media, E-commerce, finance and other majors. The originality depth and breadth of visual communication design major are expanded by establishing 'crossway' boundary resource network.

\section{Public relations network strategy}

Visual communication design education can be developed by operating various public relations networks besides professional preconditions, including teacher team relations, on-campus relations at all level, after-school professional influence, alumni circle, university-enterprise cooperation relations, international cooperation relations, etc. 


\subsection{Teacher team relations}

The teacher team depends on solidarity. The leadership skill of the leader is very important for management and mobilization of the existing teacher team. The existing teacher team has good ecological relationship; leadership strategy can be tolerant, caring and relaxed. The existing ecological relationship is not good enough; the leadership strategy should be moderately powerful and temper justice with mercy.

\subsection{On-campus relations at all level}

On-campus relations at all level should be managed well, which is helpful to comprehend on-campus information and facilitate affair transaction. Meanwhile, the impression of the major on all departments of the school will be affected.

\subsection{After-school professional influence}

Well-known subject leader are required in after-school professional influence firstly, the major should be operated for many years, and the trained students have good professional qualities. Major social effects are formed through reputation recommendation. Thirdly, professional teachers have strong professional ability, and participate in academic exchange activities frequently. They can enter the industry circle and university mainstream circles.

\subsection{Alumni circle}

The construction of alumni relationship network is very important. The resources of previous graduates can be integrated by the alumni circle. It is one of important channels for recommending students at school for further education, internships and employment. The salon also can be held regularly, such as ' upperclassman is coming', etc. Upperclassmen can exchange with lowerclassmen in the aspects of new technology and new employment trend of visual communication design major and precious experience about how to learn in school. A long-term stable brand activity can be created for constantly gathering together alumni force.

\subsection{University-enterprise cooperation relations}

University-enterprise cooperation relation is a hot topic of recent major construction. Visual communication design major has strong professional applicability and wide application field, which is very suitable for establishing university-enterprise cooperation relations. There are two cooperation modes mainly:

The first mode is university-enterprise cooperation relation during major expansion, namely the teacher-student team can guide enterprises in cooperation according to research achievements for dozens of years. It is a cooperation mode with university in the dominant position.

Another mode is university-enterprise cooperation relation during weak period of the major. 'All cooperation should be successful'. A friendly, pleasant and sustainable relationship network should be formed. The speaking right in cooperation with enterprise can be finally obtained by price/performance ratio and service quality.

\subsection{International cooperation network}

International cooperation has a strong relationship with urban platform, school brand and major reputation. The design and creative college of Tongji University is worthy of reference in the aspect. Its international cooperation network has been basically perfect. It has prominent highlights compared with the other domestic universities.

In general, there are many forms of international cooperation teaching:

1. Short term design working camp: friendly relations can be established with overseas designers and professors;

2. Student work exhibition can be held and books can be published jointly with overseas cooperation universities;

3. Six-month international exchange program;

4. Overseas vocational training for backbone teachers;

5. Professional teachers are regularly dispatched to overseas universities as visit scholars;

6. ' $3+2$ ' mode overseas master docking project of visual communication design major, etc. 
These cooperation relation networks are gradually established. There are few resources for international cooperation in the early stages of construction, and the major can starts with short-term project cooperation as pilots as far as possible, international cooperation resources should be selected in the middle and later stages of construction, visit scholar or master degree project cooperation can be carried out selectively.

In a word, teaching system environment strategy, teacher-student interactive network strategy, ecological teaching network strategy, boundary resource network strategy and public relations network strategy form an organic integrity, they are mutually associated and affected. Five teaching field innovation strategies are extracted and analyzed on the basis of the author's thinking on daily teaching work. The author tries to establish a 'student-oriented' visual communication design education ecological system, thereby making own contribution to design education.

\section{References}

[1]. Liu Shengquan, on educational field. Peking University Educational Review, Beijing Normal University Press, 2006 (1):78-91;

[2]. Jiang Dan, Innovative study of field investigation method based on field theory in landscape planning and design teaching. Decoration, 2013 (6) : 135-136.

[3]. Ji Qian, Field study of 'design city'- a culture generation. Beijing: Central Academy of Fine Arts, 2009 